mittees, members, and chapters, as well as through collaboration with other organizations, groups, and agencies. Table 4 lists some current collaborative activities.

Since its beginnings, infection control has been an evolving practice. Some changes have been subtle, and others have been very dramatic. Between the impact of Human Immunodeficiency Virus and Acquired Immunodeficiency Syndrome, the reemergence of old enemies such as tuberculosis, and the emergence of newly identified infectious agents and old agents resistant to most antibiotics, as well as more and more infection control-related regulatory requirements, the future of infection control as a profession and APIC as an organization has nowhere to go but up.

APIC and its members are indebted to the many individuals who have brought the organization to this point. Its future will continue to grow as a direct result of today's and tomorrow's members who dedicate their time and efforts to its growth.

\section{REFERENCES}

1. Castle M, Klimek JJ, eds. Association for Practitioners in Infection Control and the American Journal of Infection Control after twenty years: a review. Am J Infect Control 1992;20:1-3.

2. Soule B. The evolution of our profession: lessons from Darwin. Am J Infect Control 1991;19:45-57.

\section{TABLE 4}

Collaborative Activities

APIC/SHEA (Society for Healthcare Epidemiology of America) Quality Indicator Task Force

JCAHO Task Force (includes a SHEA liaison)

Active participation in the National Federation of Specialty Nursing Organizations and American Nursing Association's Nursing Organization Liaison Forum

International Task Force, which recently returned from taking a delegation of APIC members to Russia

OSHA and CDC liaisons sit on Government Affairs Committee and Guidelines Committee respectively

Participating member of the International Federation of Infection Control organizations

Represented on AHA's Technical Panel on Infections in Hospitals and the National Foundation for Infectious Diseases (NFID) Adult Immunization Panel

Member CDC/NFID/SHEA/APIC Coordinating Committee, and all other subsequent committees, for the 4th Decennial International Conference on Nosocomial Infections to be held April 16-19, 2000.

\title{
Rules on HIV Testing of Source Patients
}

\section{by Gina Pugliese, RN, MS Medical News Editor}

According to the AIDS Policy Center of the Intergovernmental Health Policy Project, Washington DC, 31 states have legislation addressing whether source patient consent is required for HIV testing when a healthcare worker sustains a needlestick injury or other blood or body fluid exposure. Informed consent for HIV testing of the source patient is not required in situations involving healthcare worker exposures to a patient's blood or body fluids in 15 states: Arkansas, Colorado, California, Delaware, Idaho, Illinois, Kentucky, Michigan, Mississippi, New Mexico, Tennessee, Texas, Utah, Virginia, and Wisconsin. Seven states allow testing without consent on previously obtained blood samples: Connecticut, Montana, Nebraska, North Dakota, Pennsylvania, Rhode Island, and Wyoming. Eight states allow healthcare workers to obtain a court order for testing following exposure: Connecticut, Florida, Maine, Nebraska, Ohio, Oregon, Washington, and Wyoming. Hawaii allows testing to be performed if a physician determines that the patient is incapable of giving consent. Iowa, Minnesota, and Maryland require some form of consent from either the patient or the patient's family. Other states may have health department regulations that pertain to this issue.

FROM: State laws on source patient consent for HIV testing after healthcare worker exposure. Advances in Exposure Prevention 1995;1(4) May/June 1995:8. 